\title{
PENDAMPINGAN PEMBUATAN KERAJINAN TANGAN DARI KAIN FLANEL UNTUK MENUNJANG PEREKONOMIAN KELUARGA SEBAGAI USAHA KECIL MENENGAH (UKM) MASYARAKAT DI KELURAHAN SEI LANGKAI
}

\section{ASSISTANCE IN MAKING HANDICRAFTS FROM FLANNEL FABRIC TO SUPPORT THE FAMILY ECONOMY AS A SMALL AND MEDIUM ENTERPRISE (UKM) SOCIETY IN SEI LANGKAI VILLAGE}

\author{
Yesi Gusmania ${ }^{1}$, Fitrah Amelia ${ }^{2}$ \\ Prodi Pendidikan Matematika, FKIP, Universitas Riau Kepulauan, Indonesia \\ Iemail:yesigusmania18@gmail.com, ${ }^{2}$ email:fitrahamelia@yahoo.com
}

\begin{abstract}
Abstrak
Pengabdian masyarakat ini bertujuan sebagai salah satu kegiatan untuk dapat meningkatkan kemampuan masyarakat dalam menunjang perekonomian keluarga sebagai Usaha Kecil Menengah (UKM). . Berdasarkan survey lapangan dengan masyarakat $R W 02$ kelurahan sei langkai bahwa tingkat kesejahteraan masyarakat di Kavling Nato masih tergolong rendah, hal ini terlihat dari $50 \%$ dari total jumlah penduduk di Kavling Nato termasuk ke dalam pra Keluarga Sejahtera. Selain itu, di Kavling Nato khususnya RW 02 masih banyak ibu-ibu rumah tangga yang cenderung belum mempunyai keahlian atau kegiatan sampingan. Hal ini disebabkan karena kurangnya kreativitas dalam melatih pola pikir masyarakat sebagai runtinitas sehari-hari. Salah satu cara yang digunakan untuk meningkatkan minat masyarakat, dengan memberikan motivasi dan semangat untuk ibu-ibu dalam mengembangkan Usaha Kecil Menengah (UKM) terutama pembuatan kerajinan tangan dalam menunjang perekenomian keluarga. Hasilnya menunjukkan bahwa: (1) Masyarakat sangat antusias dan semangat, ketika ibuibu diberikan keterampilan kerajinan tangan dan direspon dengan baik. (2) Pelaksanaan program pengabdian pada masyarakat ini sangat bermanfaat bagi masyarakat, sehingga dapat dilaksanakan oleh warga di kavling nato sei langkai.
\end{abstract}

Kata Kunci : kerajinan tangan, kain flanel, usaha kecil mengah (UKM)

\section{Abstract}

This community service aims as one of the activities to be able to improve the ability of the community to support the family economy as a small and medium enterprise (SMEs). Based on the field survey with the RW 02 community in the sungai langkai village the level of welfare of the people in Nato plots is still relatively low, as seen from $50 \%$ of the total population in Nato plots, including the Pre-Prosperous Family. In addition, there are still many housewives in Kavling Nato who tend not to have expertise or side activities. This is due to a lack of creativity in training the mindset of the people in various daily runtimes. One way that is used to increase public interest, by providing motivation and enthusiasm for mothers in developing small and medium enterprises (UKM), especially making crafts in supporting the family economy. The results show that: (1) The community is very enthusiastic and spirit, when mothers are given handicraft skills and responded well. (2) The implementation of the community service program is very beneficial for the community, so that it can be carried out by residents in the Nato plots Sei Langkai.

Keywords: Handcrafts, Flannel, Small And Medium Enterprises (SMEs)

\section{PENDAHULUAN}

Kelurahan Sei Langkai berbatasan langsung dengan wilayah lain di sekitarnya, yakni sebelah utara Kelurahan Buliang, sebelah selatan Kelurahan Sei Pelunggut, barat Kelurahan Sei 
Lekop dan Timur dengan Kelurahan Tembesi. Sebagian besar penduduk di Kavling Nato kelurahan sei langkai berprofesi sebagai buruh, Pengawai Swasta dan Pengawai Negeri Sipil (PNS) dan ada juga yang pedagang, seperti pedagang asongan atau pedagang kuliner. berdasarkan dari kenyataan di lapangan bahwa tingkat kesejahteraan masyarakat di Kavling Nato masih tergolong rendah, hal ini terlihat dari 50\% dari total jumlah penduduk di Kavling Nato termasuk ke dalam pra Keluarga Sejahtera. Selain itu, di Kavling Nato masih banyak ibuibu rumah tangga yang cenderung belum mempunyai keahlian atau kegiatan sampingan untuk dapat meningkatkan kemampuan mereka dalam menunjang perekonomian keluarga sebagai Usaha Kecil Menengah (UKM).

UKM mempunyai peran yang strategis dalam pembangunan ekonomi nasional. Saat ini UKM telah berkontribusi besar pada pendapatan daerah maupun pendapatan Negara Indonesia. Selain berperan dalam pertumbuhan ekonomi dan penyerapan tenaga kerja juga berperan dalam pendistribusian hasil-hasil pembangunan (Riyadi, 2014). Dalam krisis ekonomi yang terjadi di Indonesia sejak beberapa waktu yang lalu yang menyebabkan banyak usaha berskala besar yang mengalami stagnasi bahkan berhenti aktifitasnya, sektor UKM terbukti lebih tangguh dalam mengalami krisis tersebut. Terkait hal tersebut, Desa Nato Permata Khusus RW 2 Kelurahan Sei Langkai sendiri memiliki SDM yang lumayan banyak dan sangat bermanfaat untuk berlangsungnya UKM di Kavling Nato tersebut.

Pada dasarnya program pengabdian masyarakat ini adalah hasil kolaborasi dengan masyarakat di Kavling Nato yang memiliki keterampilan tangan dalam merajut dan membuat kerajinan tangan dengan menggunakan kain flanel. Kerajinan tangan itu sendiri adalah hal yang berkaitan dengan buatan tangan atau kegiatan yang berkaitan dengan barang yang dihasilkan melalui keterampilan tangan (kerajinan tangan), kerajinan yang dibuat biasanya terbuat dari berbagai bahan. Dari kerajinan ini menghasilkan hiasan atau benda seni maupun barang pakai (http://id.wikipedia.org/wiki/kerajinan dalam Rahmi, 2017).

Kain flanel atau felt adalah jenis kain yang dibuat dari serat wol, tanpa ditenun. Flanel merupakan jenis kain tertua dalam sejarah manusia, lebih tua dari kain tenun dan rajut. Jenis kain flanel yang sangat rumit juga ditemukan dalam kondisi diawetkan di sebuah makam di Siberia yang berasal dari tahun $600 \mathrm{M}$ (Flanel, 2012). Kain flanel biasa digunakan sebagai salah satu bahan untuk membuat kerajinan tangan. 
Kerajinan/kria adalah jenis karya seni rupa terapan (seni pakai) yang umumnya dihasilkan melalui kerja terampil para perajinnya (Sumanto, 2011). Usaha untuk menciptakan suatu produk atau barang yang dilakukan dengan tangan dan memiliki fungsi pakai atau keindahan sehingga memiliki nilai jual (Maulana, 2015). Peluang usaha handicraft (kerajinan tangan) juga cukup menjanjikan untuk menghasilkan keuntungan. Di Indonesia sendiri banyak kerajinan tangan yang cukup terkenal hingga ke negara lain. Dengan kreativitas yang dimilikki oleh seseorang sebuah benda yang tadinya tidak terlihat bernilai jual menjadi indah dan bahkan bisa memiliki nilai jual yang tinggi. Pada kegiatan ini para ibu-ibu rumah tangga dan masyarakat diajarkan secara lebih mendalam cara pemasaran produk melalui kreativitas yang dibuat oleh ibu-ibu.

Menurut William J. Stanton (dalam Yona, 2017) produk secara sempit dapat diartikan sebagai sekumpulan atribut fisik yang secara nyata terkait dalam sebuah bentuk dapat diidentifikasikan. Sedangkan secara luas, produk merupakan sekumpulan atribut yang nyata dan tidak nyata yang didalamnya mencakup warna, kemasan, harga, presise pengecer, dan pelayanan dari pabrik dan pengecer yang mungkin diterima oleh pembeli sebagai sebuah hal yang dapat memberikan kepuasan atas keinginannya. Secara umum pemasaran dapat sebagai salah satu upaya untuk mengenalkan barang ataupun jasa melalui promosi agar para konsumen tertarik dan melakukan aksi (membeli/menggunakan) demi tercipta penawaran yang kemudian dapat memenuhi kebutuhan masing-masing. Dari beberapa atribut yang dihasilkan oleh ibu-ibu rumah tangga dan hasil kreativitasnya bagus dapat dipromosikan kepada konsumen. Promosi yang dilakukan bisa melalui bazar atau pameran.

Salah satu tujuan keterampilan tangan ini, dapat mengasah kreativitas ibu-ibu dimana kreativitas sangat diperlukan bagi keberhasilan. Kreativitas bukan hanya milik seniman, tetapi semua aspek kehidupan akan memerlukan kemampuan kreativitas untuk mengatasi masalah dan mendapatkan ide-ide yang memperbaiki karir, bisnis, dan hidupnya. Kreativitas menjaga gairah hidup dan kreativitas menjadikan hidup terus melaju (Rahmat, 2011). Program ini sangat diharapkan agar para ibu-ibu rumah tangga dan masyarakat dapat menjadi kelompok yang lebih mandiri dalam menggerakkan UKM di Kavling Nato Kelurahan Sei Langkai. 


\section{METODOLOGI}

Bahan dan alat yang digunakan dalam kegiatan ini adalah kain flanel, lem, gunting dan accessories lainnya. Pendampingan ini menggunakan metode dengan cara praktek langsung kepada ibu-ibu rumah tangga dan warga masyarakat di Kavling Nato Kelurahan Sei Langkai. Selain itu, juga diberikan materi atau teori tentang pelaksanaan kegiatan.

Tempat kegiatan dilakukan di Kavling Nato RW 02 Kelurahan Sei Langkai Kecamatan Sagulung Kota Batam. Kegiatan ini tidak sepenuhnya dilakukan setiap hari tetapi tergantung pada kesempatan dan waktu yang ada untuk ibu-ibu rumah tangga yang ikut serta dalam kegiatan ini. Pada kegiatan pembuatan kerajinan tangan dengan kain flanel terlebih dahulu disampaikan materi dan motivasi, Materi disampaikan dengan metode ceramah dan juga diberi kesempatan untuk tanya jawab. Pelaksanaan dimulai pada pukul 14.00-16.45 wib, dengan waktu yang diperlukan sekitar 2-3 jam setiap pertemuannya.

\section{PEMBAHASAN}

Menurut KBBI (2014) kerajinan adalah barang yang dihasilkan melalui keterampilan tangan (seperti tikar, anyaman, dan sebagainya); barang-barang sederhana, biasanya mengandung unsur seni; dapat pula didefinisikan sebagai usaha kecil-kecilan yang dikerjakan di rumah. Sementara itu, kerajinan tangan adalah kegiatan membuat barang-barang sederhana dengan menggunakan tangan. Salah satu bentuk kerajinan tangan dari kain flanel adalah bros jilbab dan gantungan kunci.

Kegiatan pembinaan masyarakat yang dilaksanakan di Kavling Nato Kelurahan Sei Langkai ini dimulai dengan pemberian ilmu pengetahuan mengenai proses pembuatan kerajinan tangan dari kain flanel. Antusias masyarakat pada kegiatan ini sangat baik, dimana jumlah kehadiran mencapai $85 \%$. Materi yang disampaikan berkaitan dengan pembuatan kerajinan tangan dari kain flanel.

Berdasarkan pengamatan langsung selama kegiatan pengabdian masyarakat di Kavling Nato Sei Langkai ternyata banyak dari ibu-ibu rumah tangga yang memahami dan antusias untuk membuat kerajinan dari kain flanel berbentuk kupu-kupu dan bunga berdasarkan kreativitas mereka masing-masing. Adapun manfaat yang didapat dari kegiatan ini adalah:

1. Memotivasi ibu-ibu rumah tangga untuk kreatif dalam memanfaatkan kain flanel

2. Meningkatkan nilai tambah ibu-ibu rumah tangga dalam berkreativitas 
3. Mengembangkan usaha dalam kerajinan tangan kain flanel untuk meningkatkan perekonomian keluarga.

Melalui kreativitas dalam pembuatan kerajinan tangan diharapkan akan dihasilkan produk-produk yang bernilai jual tinggi. Menurut Sari dan Wadji (2017) kreativitas adalah kemampuan untuk membuat sesuatu yang baru dan berbeda entah sifatnya masih imajiner (gagasan) atau sudah diekspresikan dalam bentuk suatu karya. Kreativitas dapat berbentuk produk seni, kesusasteraan, produk ilmiah atau mungkin bersifat prosedural atau metodelogis. Menanamkan kemandirian dengan berwirausaha dapat mempengaruhi pola pikir sekaligus dapat mengembangkan kreativitas dan juga dapat memberdayakan masyarakat untuk bisa mandiri serta mampu membuka peluang usaha sendiri (Puratiningsih \& Islam, 2017).

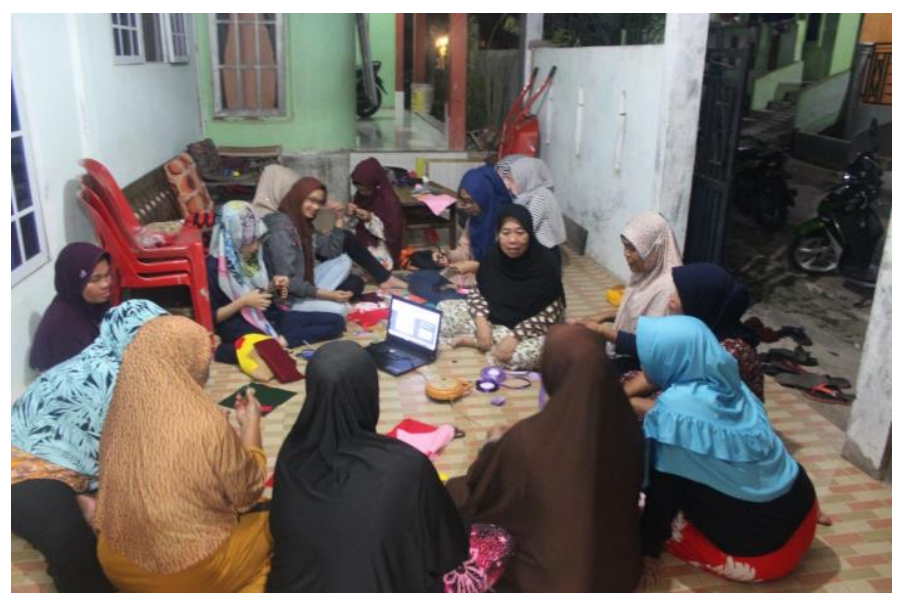

Figur 1. Memberikan pengarahan cara membuat kerajinan dari kain flanel

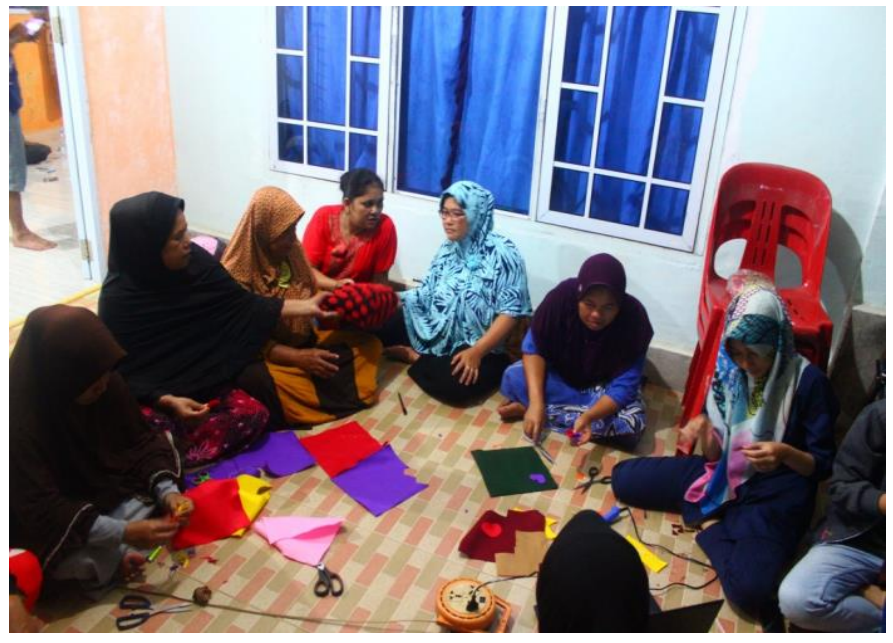

Figur 2. Proses pembuatan kerajinan dari kain flanel 

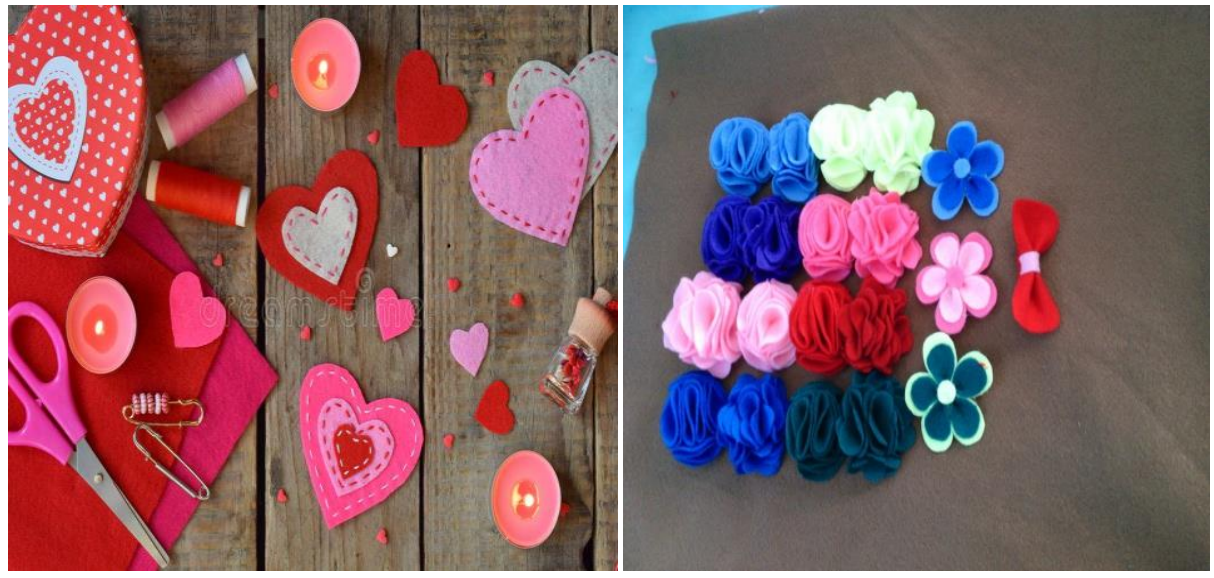

Figur 3. Hasil kerajinan tangan dari kain flanel

\section{KESIMPULAN DAN SARAN}

Berdasarkan permasalahan tersebut, maka dengan adanya pendampingan melalui kegiatan kerajinan tangan yang dilakukan di kavling Nato RW 02 Kelurahan Sei Langkai mampu memberikan motivasi dan inovasi dalam mengembangkan produk berbahan dasar kain flanel. Pelaksanaan kegiatan ini dapat berjalan dengan baik hal ini tidak terlepas dari dukungan semua pihak terutama masyarakat dan perangkat RW 02 kelurahan Sungai Langkai.

Untuk mendapatkan hasil kerajinan tangan dari kain flanel yang lebih bernilai jual disarankan untuk dapat melanjutkan kegiatan kerajinan tangan ini. Sehingga nantinya dapat menjadi salah satu sumber penghasilan bagi ibu-ibu PKK di daerah tersebut.

\section{REFERENSI}

Departemen Pendidikan Nasional. 2014. Kamus Besar Bahasa Indonesia Edisi Ke-4. Jakarta: Gramedia Pustaka Utama.

Flanel, A .2012.”Defenisi Kain Flanel” diakses dari situs azizah flanel (http://azizahflanel wordpress/com/2012/06/5/defenisi-kain-flanel)

Maulana, A. 2015. Pengertian Kerajian Tangan. Diakses pada 23 Juli 2019 dari http://www.bantubelajar.com/2015/01/Pengertian-Kerajian-Tangan.html

Purwatiningsih, B \& Islam, R., 2017. Pengembangan Kreativitas Anak Asuh melalui Handycraft Panti Asuhan Al-Amin Geluran Taman Sidoarjo. Engagement: Jurnal Pengabdian Kepada Masyarakat, 1(1). 65-75

Rahmat. 2011. 7 Tip Mengasah Kreativitas. http://www.motivasi-islami.com/7-tip-mengasahkreativitas/. 
Rahmi. 2017. Kegiatan Pelatihan Keterampilan Tangan Untuk Meningkatkan Kreativitas Ibuibu Warga Perumahan Anggara Graha RW 12 Batam. Minda Baharu: Jurnal Pengabdian Masyarakat, 1(1). 71-75

Riyadi, B., Supriadi, D.2004., Perencanaan Pembangunan daerah : Strategi Menggali potrensi dalam mewujudkan otonomi daerah. Jakarta

Sari, D. E., \& Wajdi, M. B. N., 2017. The Effectiveness Of The Method of GI With Electronic Workbench Study To Improve Activities and Results Student. Educatio: Journal of Education, 2(1), 136-150.

Sumanto. 2011. Pendidikan Senirupa di Sekolah Dasar. Malang: FIP UM.

Yona, M., 2017. Karya Kreatif yang mempunyai nilai ekonomis dengan Pemanfaatan Sampah Rumah Tangga Di Kelurahan Sei Pelunggut Kecamatan Sagulung Batam Propinsi Kepulauan Riau. Minda Baharu: Jurnal Pengabdian Masyarakat, 1(1). $42-55$ 